\title{
Commentary: Zika Virus in the Americas - Yet Another Arbovirus Threat
}

\author{
Giovanni Di Guardo* \\ Faculty of Veterinary Medicine, University of Teramo, Teramo, Italy
}

Keywords: Zika virus, arthropod-borne viruses, mosquitoes, Aedes aegypti, Aedes albopictus, Wolbachia spp., Dirofilaria immitis

\section{A commentary on}

Zika Virus in the Americas-Yet Another Arbovirus Threat

by Fauci, A. S., and Morens, D. M. (2016). N. Engl. J. Med. 374, 601-604. doi: $10.1056 /$ NEJMp1600297

As highlighted in the nice and interesting article by Drs. Anthony S. Fauci and David M. Morens, the "anthropocentric" world we live in is characterized by a progressive demographic expansion and urban population's growth, coupled with a steadily increasing trend of people's and animals' travels and movements, as well as with human-induced ecological changes (Fauci and Morens,

\section{OPEN ACCESS}

Edited by:

Sunil Kumar Lal,

Monash University, Australia

Reviewed by:

Leticia A. Carneiro,

Universidade Federal do Rio de

Janeiro, Brazil

Berlin L. Londono-Renteria,

Kansas State University, United States

*Correspondence:

Giovanni Di Guardo gdiguardo@unite.it

Specialty section:

This article was submitted to Infectious Diseases,

a section of the journal

Frontiers in Microbiology

Received: 18 January 2018

Accepted: 26 February 2018

Published: 12 March 2018

Citation:

Di Guardo G (2018) Commentary:

Zika Virus in the Americas - Yet

Another Arbovirus Threat.

Front. Microbiol. 9:435.

doi: 10.3389/fmicb.2018.00435
2016). The latter are of special concern with reference to the "ecological niches" colonized by Zika virus (ZIKV) and other arthropod-borne pathogens, either flaviviral or non-flaviviral, like Yellow Fever virus (YFV), Dengue virus (DV), West Nile virus (WNV), and Chikungunya virus (CV) (Fauci and Morens, 2016). Indeed, apart from WNV, which is mainly carried by Culex spp., Aedes (Ae.) spp. mosquitoes, particularly Aedes aegypti, are primarily involved in YFV, DV, CV, and ZIKV interhuman transmission. Within such context, the role played by Asian tiger mosquitoes (Aedes albopictus) in ZIKV ecology, epidemiology and interhuman spread deserves special attention, being Ae. albopictus far more common than Ae. aegypti in the Northern and Western Hemispheres (Fauci and Morens, 2016; Gregory et al., 2017).

Among the many challenging and open issues regarding the biology of ZIKV infection and the vertebrate/invertebrate host-pathogen interaction(s) with such virus, the only flaviviral agent with a documented teratogenic potential (Fauci and Morens, 2016), the characterization of ZIKV neurotropism and neuropathogenicity is of paramount relevance and could greatly benefit from the use of suitable animal models (Di Guardo et al., 2016; Fauci and Morens, 2016).

Furthermore, employing Wolbachia spp.-a Gram-negative bacterial microorganism infecting only invertebrates - as a "natural weapon" against ZIKV (and YFV, DV, WNV, and CV) might represent a valuable option (Gulland, 2016; Waltz, 2017). In this respect, while it has been estimated that Wolbachia spp. could infect $60 \%$ of insects worldwide, a similar situation does not appear to be true-at least under natural conditions-for Ae. aegypti. Notwithstanding the above, Wolbachia spp. has been also indicated as an efficient tool against Ae. albopictus (Waltz, 2017), which is regarded as an additional ZIKV vector, albeit with a competence and transmission capacity lower than Ae. aegypti (Fauci and Morens, 2016; Gregory et al., 2017). Indeed, utilizing a "natural weapon" like Wolbachia spp. in the fight against Ae. albopictus could lead, among others, to a reduction in the use of chemical insecticides, that are known to undergo dangerous "bioaccumulation" and "biomagnification" processes along animal food chains (Aznar-Alemany et al., 2017).

Notably, Ae. albopictus is an efficient vector for Dirofilaria immitis, a canine and feline cardio-pulmonary nematode which may also be infected by Wolbachia spp. (Morchón et al., 2012). 
Since a Wolbachia spp.-induced inflammatory response may occur in D. immitis-affected dogs and cats (Frank and Heald, 2010), I believe it would be interesting to investigate "whether and how" interfering by means of Wolbachia spp. in the ecology, epidemiology and evolution of given arthropod-borne infections could affect not only the "mosquito vector" but also the "organism" carried inside it, be it a virus (as in the case of ZIKV) or a parasite (as in the case of D. immitis). In fact, antimicrobial therapy against Wolbachia spp. has been shown to result in decreased microfilarial loads, inhibition of the development of larval worms, female worm infertility and reduced numbers of Wolbachia spp. organisms (Frank and Heald, 2010). Consequently, at least in D. immitis-infected dogs and cats, the presence and the number of Wolbachia spp. organisms appear to get along with the infection's progression, quite differently from what may be expected to occur in ZIKVinfected, Wolbachia spp.-challenged mosquitoes (Gulland, 2016; Waltz, 2017).

\section{REFERENCES}

Aznar-Alemany, Ò., Giménez, J., de Stephanis, R., Eljarrat, E., and Barceló, D. (2017). Insecticide pyrethroids in liver of striped dolphin from the Mediterranean Sea. Environ. Pollut. 225, 346-353. doi: 10.1016/j.envpol.2017.02.060

Di Guardo, G., Braga, P. B., and Peron, J. P. (2016). Zika virus-associated brain damage: animal models and open issues. Emerg. Microbes Infect. 5:e106. doi: $10.1038 /$ emi.2016.103

Fauci, A. S., and Morens, D. M. (2016). Zika virus in the Americas - Yet another Arbovirus threat. N. Engl. J. Med. 374, 601-604. doi: 10.1056/NEJMp1600297

Frank, K., and Heald, R. D. (2010). The emerging role of Wolbachia species in heartworm disease. Compend. Contin. Educ. Vet. 32:E4.

Gregory, C. J., Oduyebo, T., Brault, A. C., Brooks, J. T., Chung, K. W., Hills, S., et al. (2017). Modes of transmission of Zika virus. J. Infect. Dis. 216, S875-S883. doi: 10.1093/infdis/jix396

Gulland, A. (2016). Genetically modified mosquitoes may be used in fight against Zika. BMJ 352:i1086. doi: 10.1136/bmj.i1086

Ligios, C., Cancedda, M. G., Carta, A., Santucciu, C., Maestrale, C., Demontis, F., et al. (2011). Sheep with scrapie and mastitis transmit infectious prions through the milk. J. Virol. 85, 1136-1139. doi: 10.1128/JVI.02022-10
Noteworthy, host's inflammatory responses can modulate pathogens' shedding and transmission dynamics, as clearly documented in Streptococcus pneumoniaechallenged mice (Zafar et al., 2017) and in Scrapieinfected sheep with lentiviral mastitis (Ligios et al., 2011).

In summary, we are dealing with a very complex and intricate "balance," resulting from the mutual interaction(s) between the "pathogen," either viral (ZIKV) or parasitic (D. immitis), the "mosquito vector," the "host," and the "environment," with further investigation on these challenging and intriguing issues being absolutely needed.

\section{AUTHOR CONTRIBUTIONS}

The author confirms being the sole contributor of this work and approved it for publication.

Morchón, R., Carretón, E., González-Miguel, J., and Mellado-Hernández, I. (2012). Heartworm disease (Dirofilaria immitis) and their vectors in Europe - New distribution trends. Front. Physiol. 3:196. doi: 10.3389/fphys.2012. 00196

Waltz, E. (2017). US Government approves "killer" mosquitoes to fight disease. Nature News (November 06, 2017).

Zafar, M. A., Wang, Y., Hamaguchi, S., and Weiser, J. N. (2017). Host-tohost transmission of Streptococcus pneumoniae is driven by its inflammatory toxin, pneumolysin. Cell Host Microbe 21, 73-83. doi: 10.1016/j.chom.2016. 12.005

Conflict of Interest Statement: The author declares that the research was conducted in the absence of any commercial or financial relationships that could be construed as a potential conflict of interest.

Copyright (c) 2018 Di Guardo. This is an open-access article distributed under the terms of the Creative Commons Attribution License (CC BY). The use, distribution or reproduction in other forums is permitted, provided the original author(s) and the copyright owner are credited and that the original publication in this journal is cited, in accordance with accepted academic practice. No use, distribution or reproduction is permitted which does not comply with these terms. 